\title{
Extrato da Pimenta 'Biquinho' como revestimento comestível na conservação de goiabas
}

\section{Pepper Extract 'Biquinho' as an edible coating on conservation of guavas}

\author{
Emanuelly Rodrigues Dantas ${ }^{1}$, Alfredina dos Santos Araújo ${ }^{2}$, Everton Vieira da Silva ${ }^{3}$, Yaroslávia Ferreira Paiva ${ }^{4}, J_{o e l i t o n}$ \\ Alves Calado ${ }^{5}$, Rafael Rocha de Lima ${ }^{6}$
}

\begin{abstract}
Resumo: Pertencente à espécie Capsicum chinense, a pimenta 'Biquinho' se diferencia das demais devido a características como formato, cor e ausência de pungência. Atualmente o seu uso é limitado basicamente na ornamentação de pratos, sendo deixado de lado os inúmeros benefícios existentes. O trabalho teve como objetivo elaborar um revestimento comestível com diferentes concentrações de extrato da pimenta 'Biquinho' para auxiliar na conservação de goiabas. Os extratos foram obtidos seguindo o método de extração alcoólica, incorporados no revestimento comestível elaborado, os mesmos foram aplicados por imersão nas furtas para proceder as análises.Os frutos em que houve a aplicação do revestimento, apresentaram grande eficiência em sua conservação, principalmente sob ação de bolores e leveduras. Os resultados físico-químicos das goiabas foram satisfatórios, principalmente quanto aos teores de vitamina $\mathrm{C}$, cuja aplicação do revestimento reduziu a degradação deste componente durante o período de análise. A comprovação efetiva da ação antifúngica do revestimento elaborado foi alcançada, assim como esperada em estudo prévios, podendo ser aplicada em goiabas e tendo retardamento no processo de senescência.
\end{abstract}

Palavras-chave: Capsicum chinense; Extrato alcoólico; Conservação de goiabas.

Abstract: Belonging to the species Capsicum chinense, 'Pout' Pepper differs from the other due to its salient characteristics of shape, color and absence of pungency, but its use is currently limited, basically in the ornamentation of dishes in cooking, being left aside the numerous other benefits chemicals existing in it. It was aimed the elaboration of edible lining with different concentrations of 'Pout' pepper extract, besides applying it in the conservation of guavas marketed in the backwoods of Paraiba. For this, the extracts were obtained following to the method of extracting alcohol, incorporated in the coating prepared edible, applied by immersion in the steal and conducted the analyzes. The microbiological results, fruits in which there was the application of the coating, in other words, with extract present, showed a great efficiency in their conservation, especially under the action of yeasts and molds in the fungicidal action was not observed in the guavas were applied to the coating with a greater quantity of extract. Concerning to physical-chemical, all the guavas have achieved good results, especially in the quantification of vitamin $\mathrm{C}$, that the application of the coating caused a lower degradation of vitamin according to the period of analysis. It remains clear then, the effective proof of the action of the edible coating elaborated, thus understanding the proposed objective. The effective proof of the antifungal action of the elaborated coating was achieved, as expected in previous studies, and could be applied in guavas and delayed in the senescence process.

Key words: Capsicum chinense; Alcohol extract; Guava preservation.

\footnotetext{
*Autor para correspondência

Recebido para publicação em 09/08/2017; aprovado em 30/09/2017

${ }^{1}$ Graduanda de Engenharia de Alimentos, Universidade Federal de Campina Grande, Pombal, Paraíba; (83) 9 9655-3284, emanuellyrodrigues1@ hotmail.com.

${ }^{2}$ Profa. Dra. da Unidade Acadêmica de Tecnologia de Alimentos, Universidade Federal de Campina Grande, alfredina@ccta.ufcg.edu.br.

${ }^{3}$ Doutor em Química, Universidade Federal da Paraíba, João Pessoa, Paraíba,evertonquimica@ hotmail.com.

${ }^{4}$ Mestranda em Sistemas Agroindustriais, Universidade Federal de Campina Grande, yaroslaviapaiva@gmail.com.

${ }^{5}$ Graduado em Engenharia de Alimentos, Universidade Federal de Campina Grande, joelitonlys7@ gmail.com.

${ }^{6}$ Graduando em Agronomia, Universidade Federal de Campina Grande, rafarocha.0404@ hotmail.com.
} 


\section{INTRODUÇÃO}

Os vegetais participam da vida humana desde os primórdios, como fonte de alimentos. (SIMÕES, 2010; BOROWSKI, 2015). Possivelmente as pimentas foram os primeiros aditivos alimentares utilizados pelas civilizações antigas do México e da América do Sul, atribuindo de aroma, cor e sabor aos alimentos, tornando-as mais atraentes (GRAVINA et al, 2009).

Em termos botânicos, as pimentas têm frutos do tipo baga, de múltiplas formas, coloração e pungência. A coloração inicial do fruto é verde e quando maduro apresentase na cor vermelha. Seu formato também varia de acordo com a espécie, com a existência de frutos alongado, arredondados, triangulares ou cônicos (KAPPEl, 2007).

A pimenteira pertence à família das Solanáceas e ao gênero Capsicum, que pode ser largamente produzida nos solos e climas brasileiros, sendo encontrados diversos tipos de variedades (EMBRAPA HORTALIÇAS, 2014). Esse gênero se caracteriza por uma grande diversidade genética que possui 30 espécies identificadas (DEWITT; BOSLAND, 2009). Dentre eles, o Capsicum chinense que é considerado um tipo de variedade relativamente novo e que tem ganhando relevância nacional por apresentar frutos doces, saborosos e aromáticos (DANTAS, 2014).

A pimenta Capsicum apresenta expressiva importância econômica no agronegócio mundial, onde o seu aproveitamento está associado aos temperos usados na culinária. Elas também constituem matéria-prima para extração de corantes, aromatizantes e oleorresinas, substâncias utilizadas em produtos alimentícios, por conferir sabor e aumentar a estabilidade oxidativa dos lipídios (PINTO, 2013).

A pimenta 'Biquinho' é uma variedade que tem ganhado destaque em pesquisas científicas. Devido a sua utilização como complemento estético de pratos em restaurantes, ficando em segundo plano suas propriedades benéficas. Isso tem chamado a atenção de pesquisadores, devido à inexistência de pungência esta espécie tem agrado o paladar de indivíduos em diversas idades (DANTAS, 2015).

Existe um grande interesse por parte da indústria em plantas com princípios ativos de ação antioxidante, para que sejam utilizados de forma a contribuir na conservação de alimentos. As pimentas do gênero Capsicum são fontes de antioxidantes naturais, ricas em vitamina $\mathrm{E}$, vitamina $\mathrm{C}$ e carotenoides, carotenoideselas conferem proteção contra componentes carcinogênicos e retardam envelhecimento precoce (COSTA et al., 2009; PINTO, 2013). Uma forma de utilização é o emprego destes compostos em revestimentos naturais, contribuindo na conservação alimentícia.

O processo senescência de goiabas ocorre logo após a colheita, atingindo seu completo amadurecimento entre 3 e 5 dias (MANICA et al., 2000; GONGATTI NETTO et al., 1996). Essa característica aflige o mercado, que exige formas de retardar este processo para aumentar o tempo de comercialização.

A tecnologia de aplicação de revestimentos comestíveis tem se destacado por elevar o tempo de conservação permitindo uma maior flexibilidade de manuseio e comercialização (FONSECA; RODRIGUES, 2009). Uma vez que ao serem colhidas, a maioria das frutas, especialmente no ambiente tropical, apresentam aceleração da maturação e deterioração rápida. Estes revestimentos comestíveis, atuam como barreira de gases e vapor de água, além de atuarem como carregadores de compostos antimicrobianos, antioxidantes (LUVIELMO, 2012).

Na busca de substâncias com capacidade antimicrobiana se encontram os vegetais, principalmente devido aos compostos derivados de vias metabólicas, estes são utilizados na proteção e defesa contra predadores. O composto de notoriedade nos vegetais são os fenólicos, que se destaca por apresentar atividade microbiana (KAPPEL, 2007; OLIVEIRA, 2011).

Este trabalho teve como objetivo destacar a potencialidade da pimenta 'Biquinho', na utilização de um revestimento comestível para frutos, além de verificar a sua ação como inibidor de microrganismos deteriorantes.

\section{MATERIAL E MÉTODOS}

\section{Aquisição das pimentas e das goiabas}

A obtenção das pimentas 'Biquinho' foi através de uma parceria com Projeto Uruçu, localizado na zona rural do município de São João do Cariri no Estado da Paraíba. O projeto foi selecionado devido atuar na obtenção de pimentas e hortaliças pelo método hidropônico que é considerado totalmente orgânico.

Após a aquisição das pimentas, estas foram transportadas em caixas isotérmicas para o Centro Vocacional Tecnológico (CVT). Uma seleção prévia já havia sido realizada na hora da colheita, após a chegada no laboratório, as pimentas passaram por outra seleção. As mesmas foram sanitizadas e secas, para proceder a retirada dos talos, esse procedimento foi realizado para evitar que a água utilizada na sanitização não causasse injurias ao fruto, após esse processo as pimentas foram cortadas para facilitar o processo de secagem.

A secagem foi realizada em estufa micro processada de circulação de ar na temperatura de $65^{\circ} \mathrm{C}$ por aproximadamente 48 horas, conforme metodologia descrita em Silva (2013), foi realizado uma análise termogravimétrica e observou-se que nessa temperatura as propriedades físicas e físico-químicas da pimenta 'Biquinho' ainda não se encontravam alteradas, assim tornou-se o processo de secagem mais rápido e industrial, sem deixar de ser eficiente. Logo após realizou-se uma uniformização da granulometria passando a pimenta 'Biquinho', já seca, por um moinho de facas obtendo assim uma farinha fina.

O fruto escolhido para aplicação em estudo foi a goiaba, tendo em vista o seu curto tempo de consumo, antes que a mesma entre no processo de senescência e consequentemente não possa ser mais consumida. As amostras foram adquiridas na feira livre da cidade de Pombal-PB, logo após os frutos foram transportados para o laboratório do Centro Vocacional Tecnológico (CVT) da Universidade Federal de Campina Grande no Campus Pombal-PB, as goiabas foram selecionadas e sanitizadas por 5 minutos, em solução de água sanitária, contendo, aproximadamente, $150 \mathrm{mg} \mathrm{L}-1$ de cloro residual livre por litro de água (aproximadamente 7,5 $\mathrm{mL}$ de água sanitária para $1 \mathrm{~L}$ de água) e posteriormente imersas em agua destilada para completa retirada de resíduos.

\section{Métodos para Obtenção dos Extratos}

Em um recipiente de vidro, com tampa e protegido da luz, foi colocado aproximadamente $100 \mathrm{~g}$ da farinha de pimenta 'Biquinho' e adicionado cerca de $60 \mathrm{~mL}$ de etanol puro. Depois disso, houve a incubação sob agitação em uma 
temperatura de $25{ }^{\circ} \mathrm{C}$ por aproximadamente 50 minutos, os extratos foram deixados em repouso por 24 horas para decantação das partículas mais densas.

Após a extração foi realizada uma filtração a vácuo para remover o etanol presente no líquido, com o auxílio do aparelho de Soxhlet da Marqlabor, permanecendo na temperatura de $65{ }^{\circ} \mathrm{C}$, repetindo o processo de eliminação do solvente duas vezes para uma melhor garantia.segurança. $\mathrm{O}$ material obtido foi colocado em um recipiente de vidro, protegido da luz e posto em uma estufa de circulação de ar na temperatura de $65{ }^{\circ} \mathrm{C}$ por 30 minutos, assim obtendo um extrato pastoso, que foi utilizado na elaboração do revestimento comestível.

\section{Elaboração do Revestimento Comestível}

Seguindo a metodologia proposta por Rodrigues (2016), os revestimentos foram elaborados seguindo duas formulações, tendo como distinção a quantia de extrato adicionado, sendo as concentrações utilizadas foram testadas anteriormente. As formulações propostas encontram expostas na Tabela 1. Foi utilizado componentes simples que tornasse o revestimento menos sintético possível.

Tabela 1. Formulações dos revestimentos comestíveis a partir do extrato de pimenta 'Biquinho'.

\begin{tabular}{cc}
\hline Formulação 1 & Formulação 2 \\
\hline 0,7g sacarose & $0,7 \mathrm{~g}$ sacarose \\
1,7g Açúcar invertido & $1,7 \mathrm{~g}$ Açúcar invertido \\
4g amido de milho & $4 \mathrm{~g}$ amido de milho \\
$100 \mathrm{ml}$ água & $100 \mathrm{ml}$ água \\
$1 \mathrm{ml}$ de extrato de pimenta & $5 \mathrm{ml}$ de extrato de pimenta \\
de bico & de bico \\
\hline
\end{tabular}

Em um recipiente sob uma chapa aquecedora com agitação constante, os componentes do revestimento foram sendo adicionados e misturados apara uma total incorporação, até atingir auma temperatura de $70^{\circ} \mathrm{C}$, para maior dissolução dos ingredientes e evitar que alguns microrganismos contaminasse o material. Os dois recipientes contendo as amostras foram submetidas a um aquecimento em forno micro-ondas em pequenos intervalos de tempo, até obtenção de uma textura mais viscosa, na qual pudesse aderir ao fruto.

\section{Aplicações do revestimento na fruta}

As formulações foram aplicadas nos frutos através da imersão dos mesmo na solução, deixadas por aproximadamente 30 segundos para que pudesse o revestimento aderisse a casca do fruto e após retirada, deixouse em repouso em temperatura ambiente até que ficassem secas.

Os frutos foram submetidos às análises microbiológicas e físico-químicas. As goiabas foram armazenadas durante 18 dias, realizando-se análises a cada 3 dias. As goiabas foram identificadas como GC: goiaba controle sem revestimento, CR1: goiaba com revestimento de formulação com $1 \mathrm{ml}$ de extrato de pimenta de bico e CR2: goiaba com revestimento de formulação com $5 \mathrm{ml}$ de extrato de pimenta de bico. As mesmas foram estocadas em bandejas individuais de poliestileno embaladas com um filme plástico PVC. Em seguida, as mesmas foram colocadas em geladeira comum a fim de reproduzir a estocagem convencional. O trabalho foi realizado em Deliniamento Inteiramente Casualizado.

As amostras foram submetidas à avaliação microbiológica conforme a Resolução RDC n. 12, de 02 de janeiro de 2001 da ANVISA - Agência Nacional de
Vigilância Sanitária, sendo adotados os parâmetros de coliformes a $35^{\circ} \mathrm{C}$ e $45^{\circ} \mathrm{C}$, Escherichia coli, Salmonella sp conforme metodologias descritas pela Apha (2001) e Silva (2010).

Coliformes à $35^{\circ} \mathrm{C}$ e à $45^{\circ} \mathrm{C}$ : Cada diluição foi semeada em três tubos, contendo caldo Lauril Sulfato Triptose (LST), para realização do teste presuntivo/24h a $35^{\circ} \mathrm{C}$. Em seguida transferiu-se uma alíquota dos tubos positivos para cultura em meio Caldo Verde Bile Brilhante durante $24 \mathrm{~h}$ a $35^{\circ} \mathrm{C}$ para a quantificação do número mais provável de coliformes a $35^{\circ} \mathrm{C}$. Após esse procedimento, os tubos que apresentaram turvação e/ou bolhas (considerados positivos) foram repicados para o meio de cultura Caldo EC e incubados a $45^{\circ} \mathrm{C}$ por $48 \mathrm{~h}$, para a quantificação de Coliformes a $45^{\circ} \mathrm{C}$.

Escherichia Coli: Após a quantificação de Coliformes à $45^{\circ} \mathrm{C}$, os tubos que apresentaram turvação e/ou bolhas (considerados positivos) foram repicados para placas de Petri contendo o meio de cultura Ágar EMB, sendo incubadas a 35$37^{\circ} \mathrm{C}$ por 48 horas, para a identificação da presença/ausência de Escherichia Coli.

Salmonela sp.: Pipetou-se assepticamente $0,1 \mathrm{ml}$ da diluição de 10- 1 para cada amostra, colocou-se em placas de Petri identificadas, contendo meio $\mathrm{R}$ ambach, invertidas $\mathrm{e}$ incubadas à $35-37^{\circ} \mathrm{C}$, por 48 horas.

As características físico-químicas realizadas foram $\mathrm{pH}$, acidez titulável, sólidos solúveis e vitamina $\mathrm{C}$ seguindo as normas e procedimentos do Instituto Adolfo Lutz, 2008.

Os resultados foram submetidos à análise de variância, pelo teste de Tukey com comparação de médias ao nível de significância de 5\%, tento como auxilio o software Assistat (SILVA; AZEVEDO, 2016).

\section{RESULTADOS E DISCUSSÃO}

Durante os dias de análises não foram identificados a presença de Coliformes à $35^{\circ} \mathrm{C}$ e a $45^{\circ} \mathrm{C}$, também não foi encontrada Salmonella sp. nas amostras de (GC, GR1 e GR2), como expressas na Tabela 2, estando as goiabas de acordo com a RDC no 12 da ANVISA (2001), que prevê ausência de Salmonella sp. e um limite de $5 \times 10^{2} \mathrm{NMP} / \mathrm{ml}$ para Coliformes à $45^{\circ} \mathrm{C}$ (BRASIL, 2001). Estes dados comprovam que houve qualidade nas etapas de colheita, transporte, higienização e acondicionamento das mesmas, sendo consideradas ideais para o consumo.

Tabela 2. Análises microbiológicas das goiabas com e sem revestimento

\begin{tabular}{cccc}
\hline Análises & GC & CR1 & CR2 \\
\hline Coliformes à $35^{\circ} \mathrm{C}(\mathrm{UFC} / \mathrm{g})$ & Ausente & Ausente & Ausente \\
Coliformes à $45^{\circ} \mathrm{C}(\mathrm{UFC} / \mathrm{g})$ & Ausente & Ausente & Ausente \\
Salmonella $\mathrm{sp} .(25 \mathrm{~g})$ & Ausente & Ausente & Ausente
\end{tabular}

GC: goiaba controle (sem aplicação do revestimento); GR1: goiaba com aplicação do revestimento de formulação com $1 \mathrm{ml}$ de extrato de pimenta de bico; GR2: goiaba com aplicação do revestimento de formulação com $5 \mathrm{ml}$ de extrato de pimenta de bico

Observou-se na Figura 1 que tanto as goiabas sem revestimento (GC), quanto as goiabas com revestimento (GR1 e GR2), não apresentaram desenvolvimento microbiológico nos tempos 0 e $3^{\circ}$ dias. A partir do $6^{\circ}$ dia de análise, iniciou-se um desenvolvimento fúngico nas amostras de GC (3,33 UFC/g), nas demais amostras com revestimento os resultados permaneceram inalterados. 
Com o passar dos dias, a GC aumentou gradativamente o desenvolvimento fúngico, obtendo contagens de $1,67 \times 10^{2}$; $2,38 \times 10^{2}$ e $2,8 \times 10^{2} \mathrm{UFC} / \mathrm{g}$, nos tempos T4, T5 e T6 $\left(9^{\circ}, 12^{\circ}\right.$ e $15^{\circ}$ dias) respectivamente, chegando a $3,4 \times 10^{2} \mathrm{UFC} / \mathrm{g}$ ao final dos 18 dias de armazenamento. Na GR1, o surgimento destes microrganismos ocorreu apenas no $9^{\circ}$ dia com 5 UFC/g e foi crescendo, apresentando valores de $3,67 \times 10,1,67 \times 10^{2}$ e $2,15 \times 10^{2} \mathrm{UFC} / \mathrm{g}$ no último tempo (18 dias). Na amostra GR2 não apresentou nenhum resultado para bolores e leveduras durante o período de análises, resultado este esperado e bem convincente para o objetivo que foi proposto.

Figura 1. Desenvolvimento de Bolores e Leveduras no período de 18 dias de acondicionamento em goiabas. GC: goiaba controle (sem aplicação do revestimento); GR1: goiaba com aplicação do revestimento de formulação com $1 \mathrm{ml}$ de extrato de pimenta de bico; GR2: goiaba com aplicação do revestimento de formulação com $5 \mathrm{ml}$ de extrato de pimenta de bico

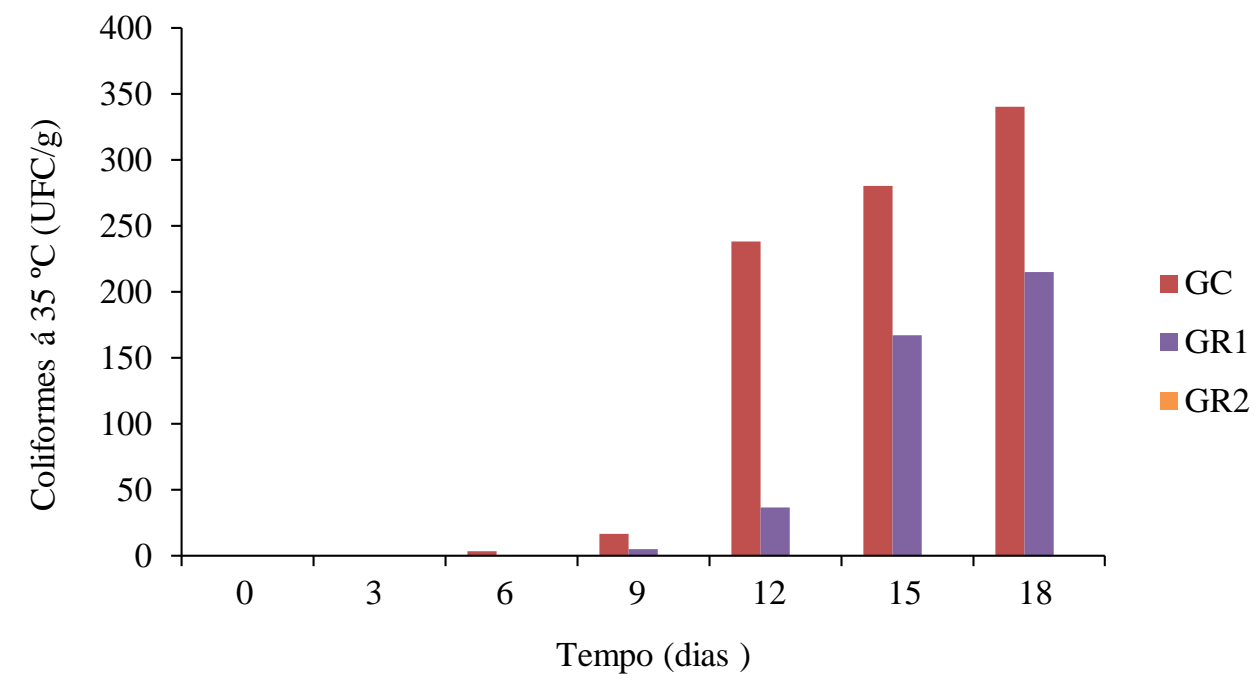

Com os resultados obtidos verifica-se atividade antifúngica do extrato da pimenta 'Biquinho', tendo em vista que, os valores durante o armazenamento nos frutos sem revestimento (GC), foram bem maiores que os apresentados nos frutos com o revestimento. Outro fator determinante foi a ampliação de 9 dias para o início do desenvolvimento dos microrganismos da amostra de goiaba com revestimento da formulação com $1 \mathrm{ml}$ de extrato de pimenta de bico (GR1), isso indica que, o extrato da pimenta 'Biquinho' mesmo que em menor concentração retardou a ação antifúngica.

Dessa forma, o revestimento aditivado do extrato da pimenta 'Biquinho' foi capaz de inibir a ação dos bolores e leveduras dos frutos, principalmente quando a concentração é maior, ou seja, quanto mais extrato utilizado no revestimento maior a sua ação. Essa qualidade aumentou a vida útil dos frutos, podendo ser considerado um método eficiente de conservação de goiabas.

Trabalhos relacionados com pimenta 'Biquinho' são bem escassos, já que sua principal utilização é na ornamentação de pratos culinários, mas em comparativos com estudos com outras espécies de pimentas, observou-se uma ação inibitória em fungos. Como analogia ao estudo de Silva (2012), cujo autor analisouin vitro extratos de pimenta malagueta e teve como resultado a fungitoxidade sobre Fusarium oxysporum f. sp vasinfectum e Pyricularia oryzae, respectivamente. Outro estudo relevante foi o de Garcia (2012), que estudou eficácia de extrato de pimenta-longa ou pimenta macaco (Piper aduncum L.) e que foi promissor na inibição do crescimento micelial, ou seja, das células de fungos. Os extratos aquosos das pimentas dedo de moça e malagueta analisados por Oliveira (2011), apresentaram taxas significativas de inibição dos fungos fitotatógenos específicos nas diversas concentrações testadas. Dessa forma, o uso desses extratos surge como uma alternativa natural de conservação de alimentos, principalmente em frutos.

Os resultados de $\mathrm{pH}$, sólidos solúveis ( ${ }^{\circ}$ brix) e acidez titulável das goiabas nos respectivos tempos de conservação estão dispostos Tabela 3.

Tabela 3. Parâmetros de pH, Sólidos Solúveis e Acidez Titulável das goiabas com e sem revestimento em 18 dias de armazenamento.

\begin{tabular}{|c|c|c|c|c|c|c|c|c|c|}
\hline \multirow[t]{2}{*}{ Dias } & \multicolumn{3}{|c|}{ Sem revestimento (Controle) } & \multicolumn{3}{|c|}{$\begin{array}{l}\text { Revestimento com } 1 \mathrm{ml} \text { de extrato de } \\
\text { pimenta de bico }\end{array}$} & \multicolumn{3}{|c|}{$\begin{array}{l}\text { Revestimento com } 5 \mathrm{ml} \text { de extrato de } \\
\text { pimenta de bico }\end{array}$} \\
\hline & $\mathrm{pH}$ & ${ }^{\circ}$ Brix & Acidez & $\mathrm{pH}$ & ${ }^{\circ}$ Brix & Acidez & $\mathrm{pH}$ & ${ }^{\circ}$ Brix & Acidez \\
\hline 0 & $4,02 \pm 0,11^{b}$ & $11,23 \pm 0,05^{\mathrm{b}}$ & $0,89 \pm 0,04^{\mathrm{a}}$ & $4,12 \pm 0,16^{\mathrm{ab}}$ & $11,93 \pm 0,15^{\mathrm{a}}$ & $0,96 \pm 0,04^{\mathrm{a}}$ & $4,22 \pm 0,25^{\mathrm{a}}$ & $10,60 \pm 0,20^{\mathrm{c}}$ & $0,94 \pm 0,03^{\mathrm{a}}$ \\
\hline 3 & $3,52 \pm 0,04^{\mathrm{a}}$ & $13,43 \pm 0,32^{\mathrm{a}}$ & $1,19 \pm 0,21^{\mathrm{a}}$ & $3,70 \pm 0,23^{\mathrm{a}}$ & $12,30 \pm 0,17^{\mathrm{b}}$ & $0,77 \pm 0,67^{\mathrm{b}}$ & $4,14 \pm 0,31^{\mathrm{a}}$ & $10,90 \pm 0,52^{\mathrm{c}}$ & $0,61 \pm 0,53^{\mathrm{c}}$ \\
\hline 6 & $4,27 \pm 0,49^{\mathrm{a}}$ & $6,90 \pm 0,65^{\mathrm{c}}$ & $0,86 \pm 0,04^{\mathrm{b}}$ & $3,70 \pm 0,36^{\mathrm{b}}$ & $9,10 \pm 0,35^{\mathrm{b}}$ & $1,12 \pm 0,06^{\mathrm{a}}$ & $3,80 \pm 0,47^{\mathrm{ab}}$ & $9,83 \pm 0,47^{\mathrm{a}}$ & $1,24 \pm 0,03^{\mathrm{a}}$ \\
\hline 9 & $4,40 \pm, 24^{\mathrm{a}}$ & $8,37 \pm 0,11^{\mathrm{c}}$ & $0,68 \pm 0,04^{\mathrm{b}}$ & $3,71 \pm 0,08^{\mathrm{a}}$ & $11,80 \pm 0,70^{\mathrm{a}}$ & $1,05 \pm 0,01^{\mathrm{a}}$ & $3,94 \pm 0,22^{\mathrm{a}}$ & $11,10 \pm 0,20^{\mathrm{b}}$ & $1,03 \pm 0,04^{\mathrm{a}}$ \\
\hline 12 & $3,91 \pm 0,06^{\mathrm{a}}$ & $11,37 \pm 0,75^{\mathrm{c}}$ & $0,75 \pm 0,65^{\mathrm{a}}$ & $3,92 \pm 0,09^{\mathrm{a}}$ & $12,17 \pm 0,40^{\mathrm{b}}$ & $0,84 \pm 0,07^{\mathrm{a}}$ & $3,87 \pm 0,70^{\mathrm{a}}$ & $12,63 \pm 0,70^{\mathrm{a}}$ & $1,01 \pm 0,27^{\mathrm{a}}$ \\
\hline 15 & $4,18 \pm 0,04^{b}$ & $11,07 \pm 0,29^{a}$ & $0,34 \pm 0,30^{\mathrm{b}}$ & $4,62 \pm 0,31^{\mathrm{a}}$ & $9,53 \pm 0,15^{\mathrm{b}}$ & $0,54 \pm 0,01^{\mathrm{a}}$ & $4,11 \pm 0,60^{\mathrm{b}}$ & $9,53 \pm 0,21^{\mathrm{b}}$ & $0,62 \pm 0,03^{\mathrm{a}}$ \\
\hline 18 & $4,02 \pm 0,15^{\mathrm{b}}$ & $11,70 \pm 0,20^{\mathrm{b}}$ & $0,68 \pm 0,03^{\mathrm{a}}$ & $4,12 \pm 0,01^{\mathrm{ab}}$ & $13,77 \pm 0,38^{\mathrm{a}}$ & $0,78 \pm 0,06^{\mathrm{a}}$ & $4,22 \pm 0,05^{\mathrm{a}}$ & $8,67 \pm 0,23^{c}$ & $0,54 \pm 0,01^{\mathrm{b}}$ \\
\hline $\begin{array}{l}\text { Média } \\
\text { Geral }\end{array}$ & $4,05 \pm 0,29^{\mathrm{A}}$ & $10,58 \pm 2,20^{A}$ & $0,77 \pm 0,26^{\mathrm{A}}$ & $3,98 \pm 0,34^{\mathrm{A}}$ & $11,5 \pm 11,64^{\mathrm{A}}$ & $0,87 \pm 0,20^{\mathrm{A}}$ & $4,04 \pm 0,17^{\mathrm{A}}$ & $10,48 \pm 1,28^{\mathrm{A}}$ & $0,86 \pm 0,27^{\mathrm{A}}$ \\
\hline
\end{tabular}


Um dos intuitos proposto neste estudo, foi que a aplicação do revestimento pudesse ser realizada de forma caseira e com fruto adquiridos no comercio local, por isso, os resultados físico-químicos observados houveram uma diferença que são justificadas por questão agronômica, em que cada fruto tinha um estádio de maturação diferente. Mas com relação à média global, destaca-se que não houve diferença significativas entre os parâmetros das amostras.

Os valores de $\mathrm{pH}$, sólidos solúveis e acidez titulável se mantiveram constantes, durante todo o período de armazenamento tanto nas goiabas controle, quanto nas goiabas com revestimento. Esses resultados também foram constatados por outros autores, como no estudo de Pereira (2006), que analisou a influência das condições de armazenamento de goiabas acondicionadas em caixa de papelão e com filme comum, o estudo obteve resultados que variaram entre $\mathrm{pH} 3,93$ a 4,48 em goiabas sem filme e $\mathrm{pH}$ 4,07 a 4,93 em goiabas com filme comum durante os 4 tempos de análises. O mesmo afirma que, os valores elevados de pH e acidez, são associados a concentração dos ácidos (ascórbico e cítrico). Outro comparativo válido é sobre o armazenamento de goiabas sob refrigeração, com e sem tratamento com cera de carnaúba, estudo este realizado por Ribeiro (2005), o autor observou que, o conteúdo de sólidos solúveis ( ${ }^{\circ}$ Brix) no $6^{\circ}$ dia de armazenamento de goiabas foram próximos dos analisados na época da colheita, sendo de 10,9 ${ }^{\circ}$ Brix, acima dos encontrados neste estudo, porém semelhante ao encontrado no T3 dos frutos GR1 e GR2, que corresponde ao $6^{\circ}$ dia.

Os teores de ácido ascórbico (mg/100g) analisados nas goiabas durante os tempos de armazenamento estão dispostos na Figura 2.

Figura 2. Teores de Vitamina $\mathrm{C}$ das goiabas com e sem aplicação do revestimento comestível, durante os 18 dias de acondicionamento. GC: goiaba controle (sem aplicação do revestimento); GR1: goiaba com aplicação do revestimento de formulação com $1 \mathrm{ml}$ de extrato de pimenta de bico; GR2: goiaba com aplicação do revestimento de formulação com 5 ml de extrato de pimenta de bico

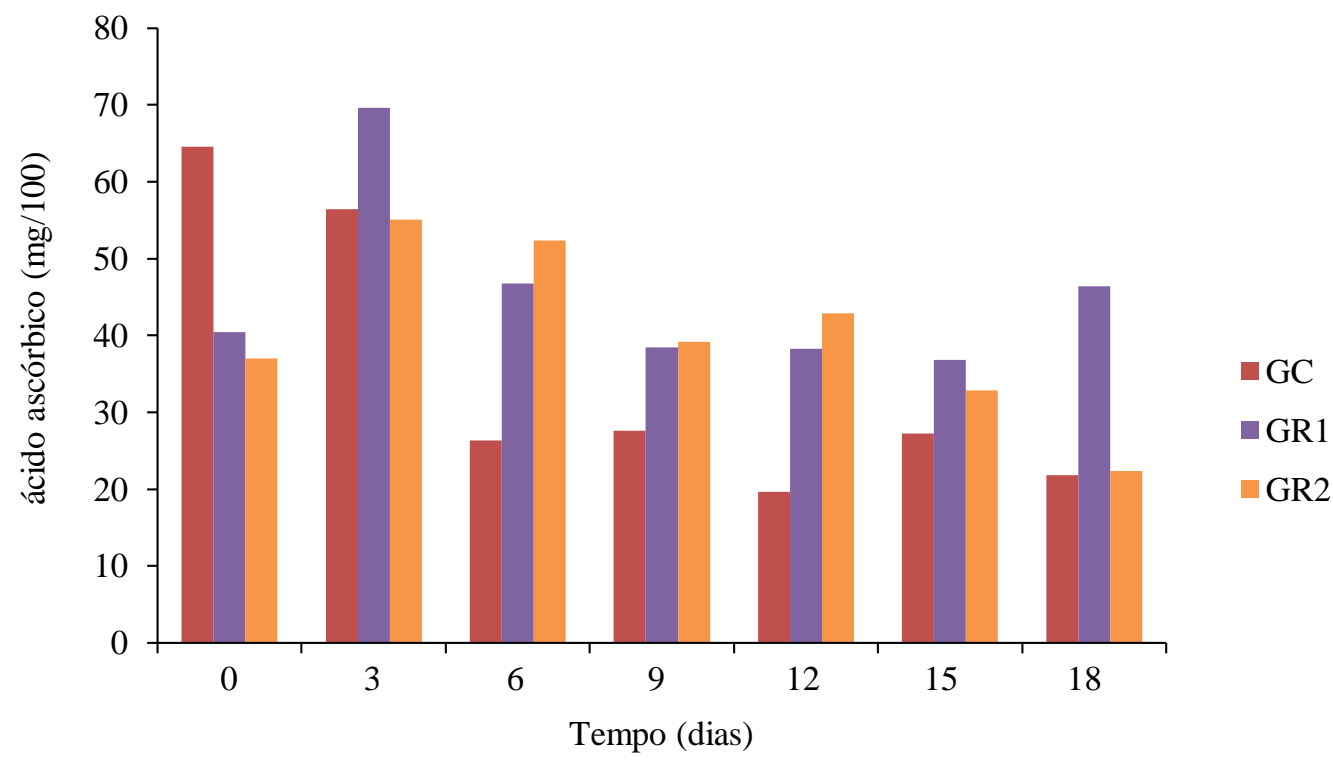

De acordo com Chitarra e Chitarra (2005), as perdas substanciais de nutrientes podem ocorrer com o armazenamento, especialmente a vitamina C. Foi observado neste experimento que, as goiabas com aplicação do revestimento mantiveram-se os níveis de ácidos ascórbico próximos durante o período de armazenamento, entretanto, verificou-se que as goiabas controles também obtiveram esse comportamento. Em pesquisa realizada por Azzolini (2004), ao avaliar goiabas em diferentes estádios de maturação, foi observado um aumento no teor de ácido ascórbico em todos os estádios de maturação, no entanto posteriormente houve uma diminuição.

Chitarra e Chitarra (2005), relata que o revestimento externo da epiderme de frutos tem função de regulação das trocas hídricas e gasosas, além da proteção contra-ataques físicos, químicos e biológico. Ao aumentar essa proteção com o uso de revestimento comestível, garante-se maior defesa do fruto contra a ação de oxigênio fazendo com que a degradação de ácido ascórbico seja menor.

\section{CONCLUSÕES}

Houve ação antifúngica do revestimento elaborado, com resultados microbiológicas satisfatórios, sem ocorrência de bolores e leveduras nas goiabas com revestimento de maior concentração de extrato com retardamento do processo de degradação da vitamina $\mathrm{C}$, devido a proteção e ação do extrato da pimenta 'Biquinho' sendo interessante a utilização do revestimento para retarda a senescência e prolonga da vida útil de frutos.

\section{REFERÊNCIAS}

ASSOCIATION OF OFFICIAL ANALYTICAL CHEMISTS - AOAC. Official Methods of Analysis. 19a edition. U.S.A, 2012. 3000p.

AZZOLINI, M.; JACOMINO, A. P.; BRON, I. U. Índices para avaliar qualidade pós-colheita de goiabas em diferentes 
estádios de maturação. Pesquisa Agropecuária Brasileira, v.39, n.2, 2004.139-145p.

BOROWSKI, V.; GOMES, R. Avaliação da atividade antibiofilme de Capsicum baccatum var. pendulum (Solanaceae).2015. 98f. Dissertação (Mestrado em Ciências Farmacêuticas) - Universidade Federal Do Rio Grande Do Sul, Porto Alegre. 2015

BRASIL, Resolução RDC. $n^{\circ} 12$, de 02 de janeiro de 2001. Dispõe sobre os princípios gerais para o estabelecimento de critérios e padrões microbiológicos para alimentos. Agência Nacional de Vigilância Sanitária (ANVISA). Disponível em: < http://www. vigilanciasanitaria. gov. br/anvisa. html>. Acessado em: 23 de janeiro de 2017.

CHITARRA, M. I. F.; CHITARRA, A. B. Pós-colheita de frutas e hortaliças: fisiologia e manuseio. Lavras: Editora da UFLA. Pesquisa Agropecuária Tropical. 2005. 94p.

COSTA, L. M.; DE MOURA, N. F.; MARANGONI, C.; SCHNEIDER, N. F. Z. Antimicrobial activity of the genus Capsicum. Higiene Alimentar. n. 174/175, 2009. 140-145p.

DANTAS, E. R.; ARAÚJO, A. S. Avaliação das propriedades físico-químicas e microbiológicas de pimenta biquinho e sua aplicação em formulações alimentícias. In: XII Congresso de Iniciação Cientifica da Universidade Federal de Campina Grande. Campina Grande, 2015.

EMBRAPA HORTALIÇAS. Perspectivas e potencialidade do mercado para pimentas. Disponível em: < www.emater.go.gov.br/intra/wp-

content/uploads/downloads/2011/07/Potencialidade-

deMercado-Pimenta.pdf $>$. Acessado em: 25 de janeiro de $/ 2017$.

FONSECA, S. F.; RODRIGUES, R. S. Utilização de embalagens comestíveis na indústria de alimentos. Pelotas, RS. Universidade Federal de Pelotas, 2009. 34 p.

GARCIA, R. Á.; JULIATTI, F. C.; BARBOSA, K. A. G., CASSEMIRO, T. A. Atividade antifúngica de óleo e extratos vegetais sobre Sclerotinia sclerotiorum= Antifungal activity of vegetable oils and extracts against Sclerotinia sclerotiorum. Bioscience Journal, v.28, n.1, 2012.

GONGATTI NETTO, A.; GARCIA A. E.; ARDITO, E.F.G. et al. Goiabas para exportação: procedimentos de colheita e pós-colheita. Brasília: EMBRAPA, SPI. 1996. 35p.

GRAVINA, O., HENZ, G. P., CARVALHO, S. I. C. Conservação pós-colheita de pimentas da espécie Capsicum chinense com filme de PVC em duas temperaturas. Disponível em: <http://www.abhorticultura.com.br/biblioteca/arquivos/Down load/Biblioteca/44_159.pdf>. Acessado em 23 de janeiro de 2017.

INSTITUTO ADOLFO LUTZ. Métodos físico-químicos para análise de alimentos. 4 ed, São Paulo: Instituto Adolfo Lutz, p. 1020,2008

KAPPEL V. D. Avaliação das propriedades antioxidantes e antimicrobiana de Extrato de Capsicum baccatum L. var. pendulum. Dissertação (Mestrado em Ciências Biológicas:
Bioquímica) - Universidade federal do Rio Grande do Sul, Porto Alegre. 2007.

LUVIELMO, M. M.; LAMAS, S. V.; Revestimentos comestíveis em frutas. Estudos Tecnológicos em Engenharia. Pelotas. v.8, n.1, 2012. 8-15p.

MANICA, I.; ICUMA, I. M.; JUNQUEIRA, N. T. V.; SALVADOR, J. O.; MOREIRA, A.; MALAVOLTA, E. Fruticultura Tropical-Goiaba. Porto Alegre: Cinco Continentes, 2000. 373p.

OLIVEIRA, A. M. C. Caracterização química, Avaliação da atividade antioxidante in vitro e atividade antifúngica de pimentas do gênero Capsicum spp. 2011. 182f. Tese (Doutorado em Ciência dos Alimentos Área de Brotamento) Faculdade de Ciências Farmacêuticas, São Paulo. 2011.

PEREIRA, T.; CARLOS, L. D. A.; OLIVEIRA, J. D.; MONTEIRO, A. R. Influência das condições de armazenamento nas características físicas e químicas de goiaba (Psidium guajava), cv. Cortibel de polpa branca. Ceres, v.53, n.306, 2006.276-287p.

PINTO, C. M. F.; PINTO, C. L. de O.; DONZELES, S. M. L. Pimenta Capsicum: propriedades químicas, nutricionais, farmacológicas e medicinais e seu potencial para o agronegócio. Revista Brasileira de Agropecuária Sustentável, v.3, n.2, 2013.

RIBEIRO, V. G.; ASSIS, J. D.; SILVA, F. F.; SIQUEIRA, P. P. X.; VILARONGA, C. P. P. Armazenamento de goiabas 'Paluma'sob refrigeração e em condição ambiente, com e sem tratamento com cera de carnaúba. Revista Brasileira de Fruticultura, v.27, n.2, 2005. 203-206p.

RODRIGUES, M. do S. A. Biofilme a base de extrato de própolis vermelha e seu efeito na conservação pós-colheita de tomate tipo italiano. Dissertações. Programa de PósGraduação em Sistemas Agroindustriais (24-Mestrado Profissional). 2016.

SILVA, E. V.; DEODATO, J. N. V; MELO, M. A. R.; SILVA, E. E. V.; SOUZA, A. G.; SOUZA, A. L.; ARAUJO, A. S. Quantificação de teores de pigmentos alimentares existentes em farelos do mesocarpo e da amêndoa do fruto do marizeiro. In: $53^{\circ}$ Congresso Brasileiro de Química, Rio de Janeiro. 53 Congresso Brasileiro de Química, 2013.

SILVA, F. A. S.; AZEVEDO, C. A. V. The Assistat Software Version 7.7 and its use in the analysis of experimental data. Afr. J. Agric. Res, v.11, n.39, p.3733-3740, 2016.

SILVA, J. L.; TEIXEIRA, R. N. V.; SANTOS, D. I. P.; PESSOA, J. O. Atividade antifúngica de extratos vegetais sobre o crescimento in vitro de fitopatógenos. Revista Verde de Agroecologia e Desenvolvimento Sustentável, v.7, n.1, p.80-86, 2012.

SIMÕES, M. O. E. A. Farmacognosia: da planta ao medicamento. 6. ed. Porto Alegre: Editora da UFRGS, 2010. $1102 \mathrm{p}$.

WITT, D.; BOSLAND, P. W. The complete chilli pepper book-A gardener's guide to choosing, growing, preserving and cooking. London: Timber Press. 2009. 336p. 